\title{
Identifikasi Peran UPT. Malioboro terhadap Penyandang difabel di Kawasan Malioboro, Yogyakarta (Analisis SOAR)
}

Asdalia Br Pasaribu a, 1, Ida Ayu Suryasih a, 2

${ }^{1}$ asdalia248@gmail.com, ${ }^{2}$ idaayusuryasih@unud.ac.id

a Program Studi Sarjana Destinasi Pariwisata, Fakultas Pariwisata, Universitas Udayana, Jl. Dr. R. Goris, Denpasar, Bali 80232 Indonesia

\section{Abstract}

This research background is the presence of persons with diffability in the Malioboro area who have not benefited from tourism activities, so that make people with diffability only show their limitations, in addition the difficulties for persons with diffability have an impact on their welfare. The Yogyakarta Government has an ambition to make Yogyakarta as an accessible city, to realizing that, the Malioboro Technical Implementation Unit has the duty to empower the community in the Malioboro area according to its role. The objectives of this study are :1) How the role of the involvement of Malioboro Technical Implementation Unit for People with diffability and 2) What is the strategy of empowering people with diffability by stakeholders in the Malioboro tourism area. The analysis in this study is a descriptive qualitative analysis in reviewing the role of a technical unit to manage the Malioboro area, called Unit Pengelola Teknis (UPT) Malioboro involved in existing conditions and SOAR analysis of identified strengths, opportunities, expectations and results to be achieved. This research located in the Malioboro area, there is a lot of people with diffability who have not paid enough attention to location.The results of the study show that the Malioboro Technical Implementation Unit has not carried out its duties in the field of empowerment and taking care of the of people with diffability. The involvement is considered low, in addition, the research indicates that many persons with diffability hope to be accommodated to receive the same tourism benefits, and are expected to be strongly involved in the future.

Keyword: Diffability, Empowerment, Technical Implementation Unit Malioboro

\section{PENDAHULUAN}

Yogyakarta merupakan sebuah destinasi pariwisata terbesar kedua di Indonesia setelah Pulau Bali, Yogyakarta telah memiliki keberagaman potensi pariwisata yang sudah lebih dulu dikenal para wisatawan baik itu mancanegara atau domestik, salah satunya adalah Kawasan Malioboro, Kawasan ini merupakan sebuah area yang di padati oleh aktifitas seluruh lapisan masyarakat dan wisatawan yang datang, meskipun demikian data yang diperoleh ternyata masih banyak lapisan masyarakat yang tidak merasakan manfaat dari adanya aktifitas pariwisata di Kawasan Malioboro yang seharus nya, seperti masyarakat Penyandang difabel

Dalam mengurangi dampak negatif pada Penyandang difabel, difabel dipandang penting sebagai elemen masyarakat lokal yang perlu diprioritaskan dalam pengembangan ekonomi serta sosial-budaya. Indikator tersebut adalah fokus penelitian yaitu peran lembaga pengelola dan pelaksana di Kawasan Malioboro yang disebut sebagai Unit Pelaksana Teknis (UPT) Malioboro kepada Penyandang difabel dan strategi pemberdayaan Penyandang difabel di kawasan tersebut juga menjadi fokus.

Tinjauan penelitian sebelumnya yang berkaitan dengan penelitian ini terdiri atas dua, yang memiliki keterkaitan antara fokus maupun lokus penelitian, penelitian pertama berjudul "Peran Unit Pelaksana Teknis Dinas (UPTD) Pondok sosial Kalijudan Kota Surabaya dalam Pembinaan anak Penyandang
Tunagrahita" dalam studinya Putri (2015) memiliki kesamaan terhadap fokus pada identifikasi peran lembaga unit pelaksana daerah dimana peneliti menjelaskan UPTD sudah melaksanakan peran nya sesuai tugas pokok dan kedudukan lembaga tersebut kemudian diindikasi dengan adanya penjaringan anak Tunagrahita yang memang memenuhi syarat untuk tahap berikutnya, pada tahap ini merupakan pengidentifikasian yang merujuk pada keahlian anak Tunagrahita, hingga tahap registrasi menjadi bagian dari unit pelaksana teknis daerah Kalijudan Kota Surabaya untuk dibina secara fisik, mental,spiritual, sosial, keterampilan dan penyediaan pelayanan pada anak Tunagrahita.

Pelayanan yang diberikan oleh UPTD Pondok Sosial Kalijudan Kota Surabaya sudah dapat memenuhi kebutuhan sandang, pangan, dan papan secara baik dan dilakukan secara rutin sehingga dapat mewujudkan kesejahteraan sosial anak penyandang Tunagrahita

Penelitian kedua dalam studinya Purita (2013), berjudul "Pengelolaan Transportasi Umum di jalan Malioboro, Yogyakarta" memiliki kesamaan lokus Kawasan Malioboro Yogyakarta, pada penelitian ditemukan bahwa kondisi jalan Malioboro dalam pengelolaan transportasi umum masih terjadi kemacetan lalu lintas, fasilitas parkir yang belum memadai, para wisatawan dan pedagang yang masih memarkirkan kendaranya di bahu jalan meskipun telah diberlakukan regulasi seperti manajemen rekayasa lalu lintas, serta pemberian sarana dan prasarana lalu lintas 
Penelitian ini memiliki kesamaan terhadap kedua penelitian sebelumnya, pada penelitian ini lebih berfokus kepada pemberdayaan yang dilakukan Unit Pelaksana Teknis Malioboro terhadap Penyandang difabel yang ada di kawasan Malioboro, sehingga dalam prosesnya diharapkan tidak hanya mengutamakan wisatawan saja tetapi membantu masyarakat lokal dalam hal ini di khususkan kepada Penyandang difabel untuk meminimalisir dampak negatif terhadap ekonomi mereka

\section{METODE PENELITIAN}

Penelitian ini dilaksanakan di Kawasan Malioboro, tepatnya di Jln Sosromenduran Gedong Tengen, Kota Yogyakarta, Daerah Istimewa Yogyakarta. Penelitian dilakukan karena melihat banyak nya Penyandang difabel yang belum mendapatkan keuntungan dari kegiatan pariwisata di Kawasan Malioboro .

Penelitian menganut paradigma penelitian kualitatif dengan metode kualitatif dan teknik penelitian kualitatif (Mahagangga, 2020). Metode pengumpulan data, menggunakan teknik observasi, wawancara (Suryawan, 2017), observasi dan studi dokumen (Bungin, 2007).

Jenis data dalam penelitian ini adalah data kuantitatif dan data kualitatif. Sumber data tersebut terdiri atas data primer dan sekunder (Bungin, 2007). Teknik analisis data yang digunakan dalam penelitian ini adalah analisis SOAR (Stavross, dkk., 2003) dengan penyajian data secara deskriptifkualitatif (Bungin, 2007).

\section{HASIL DAN PEMBAHASAN}

Kawasan Malioboro adalah sebuah kawasan sosial-ekonomi yang terbentang sepanjang kurang lebih satu kilo meter di mulai dari persimpangan rel kereta api stasiun tugu Yogyakarta diujung utara hingga perempatan Gedung Kantor Pos Indonesia diujung selatan kota Yogyakarta, Jawa Tengah

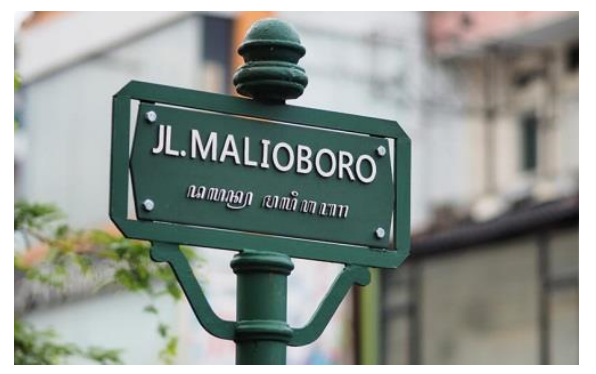

\section{Gambar 1 Lokasi Kawasan Malioboro} Sumber: google.maps

Malioboro merupakan sebuah kata yang diserap dari bahasa jawa yaitu "Mo-limo-oboro" yang berarti bakarlah molimo yang di maknai sebagai kejahatan manusia,mabuk-mabukan-mencuri. Hal itu bukan bermakna larangan untuk tidak melewati jalan Malioboro namun makna molimo dalam Malioboro itu sendiri dimaknai sebagai himbauan untuk mengihandari atau menjauhkan diri dari molimo tersebut.

Kawasan Malioboro yang ditetapkan sebagai kawasan untuk pembatas dan jalur dengan citra budaya pariwisata dan perjuangan, mempunyai batas meliputi:

1) Sebelah utara :yaitu Jalan Kyai Mojo, Jalan Pangeran Diponegoro, Jalan Jenderal Sudirman.

2) Sebelah timur : yaitu Sungai Code

3) Sebelah selatan: yaitu Jalan Panembahan Senopati dan Jalan Kyai Haji Ahmad Dahlan

4) Sebelah barat : yaitu Sungai Winongo

Kawasan Malioboro juga dijadikan sebagai mata pencarian masyarakat lokal, di kawasan ini banyak lapisan masyarakat yang ambil bagian untuk memperoleh manfaat dari aktivitas pariwisata yang padat pengunjung, serta memiliki dua sisi yang berbeda pada saat pagi dan malam harinya.

Salah satu lapisan masyarakat tersebut adalah Penyandang difabel, data terakhir pada tahun 2017 ada sekitar dua puluh tiga Penyandang difabel yang berada di kawasan Malioboro, tahun ini ada sekitar 20\% kenaikan jumlah Penyandang difabel di Kawasan Malioboro yang terdiri atas Tuna netra dan Tuna daksa

Berdasarkan data yang diperoleh, beberapa dari mereka sudah ada yang bekerja di lokasi tersebut sebelum Unit Pelaksana Teknis Malioboro dibentuk oleh Pemerintah kota Yogyakarta, berikut tinjauan tentang Peran Unit Pelaksana Teknis Malioboro pada Penyandang difabel ditinjau dari kondisi realitas berdasarkan komponen 4 a diantaranya:

\section{Atraction (Atraksi)}

Kawasan Malioboro memiliki keberagaman atraksi, salah satu atraksi yang tidak luput yaitu atraksi sejarah dan beragam atraksi sejarah itu dapat di kunjungi wisatawan pada pagi hingga sore hari, berikut beberapa daya tarik bersejarah di Kawasan Malioboro antara lain: Tugu Yogyakarta, Stasiun Tugu, Gedung Agung, Pasar Beringharjo, Benteng Vredeburg dan Monumen Serangan Oemoem 1 Maret.

Pemerintah Kota Yogyakarta saat ini sedang melakukan uji coba terkait atraksi bersepeda di seputaran Kawasan Malioboro yang didukung oleh BUMN Pertamina Indonesia menggunakan Aplikasi khusus yaitu Jogja Bike, atraksi ini berjalan sejak november tahun 2018 lalu dan aplikasi tersebut dapat di download oleh wisatawan, antusias wisatawan cukup besar terkait atraksi baru ini.

Penyandang difabel di Kawasan Malioboro juga mencoba ikut ambil bagian dengan beragam aktifitas yang mereka lakukan sebagai sebuah dengan menunjukan penampilan yang dibekali oleh alat musik seadanya seperti, pianika, angklung, suling rekorder, microphone, loudspker seadanya dan kursi, 
berikut bentuk atraksi yang dilakukan Penyandang difabel pada gambar 2

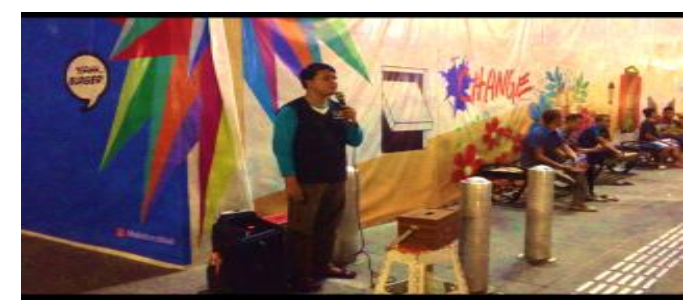

Gambar 2: Penyandang difabel Tuna Netra Sumber: Dokumentasi Penelitian

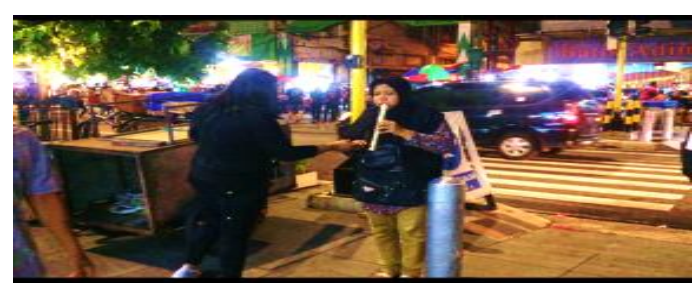

Gambar 3 : Penyandang difabel Tuna Netra Sumber: Dokumentasi Penelitian

Pada gambar tersebut menampilkan para Penyandang difabel yang menyanyi dan bermain suling, menurut wisatawan hal itu kurang efesien karena atraksi yang Difabel itu tawarkan 70\% sama dan mereka mengatakan tidak mengeluarkan uang untuk hal yang sama di lokasi yang sama dengan waktu yang sama juga, menurut mereka itu juga merugikan Penyandang difabel yang melakukan atraksi tersebut di lokasi yang sedikit lebih jauh kedalam Kawasan Malioboro karena sebelum mereka ada Penyandang difabel lain dengan atraksi yang sama di lokasi awal mereka memasuki Kawasan Malioboro sehingga tidak terjadi pemerataan pendapatan untuk masing-masing Penyandang difabel, sehingga diperlukan peran pelaksana dan pengelolan Kawasan Malioboro untuk pengaturan, perancangan dan pengemasan atraksi yang lebih baik dari Penyandang difabel agar tercipta kesetaraan antara Penyandang difabel sebagai masyarakat lokal.

\section{Amenity (Amenitas)}

Kota Yogayakarta sangat dikenal dengan campaign aksesibel terhadap Penyandang difabel, hal itu dapat dilihat langsung di Kawasan Malioboro, Pemerintah Kota Yogyakarta yang membentuk Unit Pelaksana Teknis Malioboro dalam mengatur dan mengelola kawasan itu telah berupaya membangun fasilitas-fasilitas untuk para Penyandang difabel, seperti halnya guiding block disepanjang Kawasan Malioboro guna mempermudah penyandang Tuna Netra saat berjalan di kawasan itu, seperti pada gambar 3 berikut ini

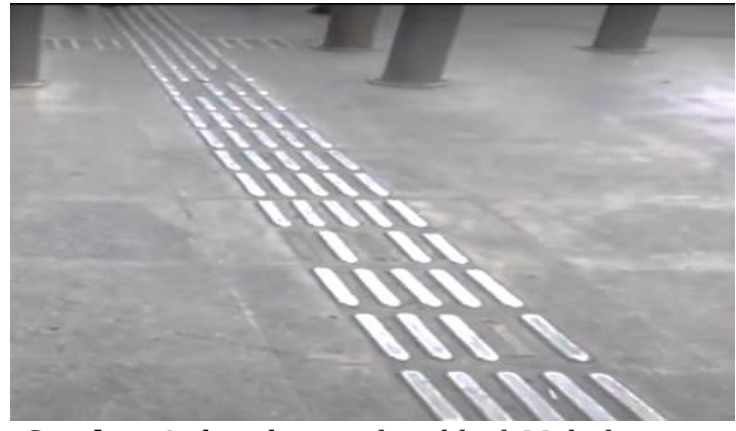

Gambar 4 : kondisi guiding block Malioboro Sumber : Dokumentasi Penelitian

Berdasarkan survey yang dilakukan organisasi Penyandang difabel di Kota Yogyakarta dan hasil observasi yang dilakukan selama penelitian, fasilitas tersebut ternyata belum cukup aksesible

Menurut pandangan wisatawan secara umum cukup memandang kawasan Malioboro sebagai kawasan yang aksesible, tetapi bagi Penyandang difabel itu sendiri masi belum cukup memadai, alasanya adalah pemilihan material dalam guiding block pada Kawasan Malioboro, dalam penjelasan mereka kondisi itu hanya dapat memenuhi 45\% kebutuhan para penyandang tuna netra.

Hal tersebut dapat dilihat dari penggunaan material yang digunakan berupa material terbuat dari alumunium dan berwarna abu-abu, secara tekstur material yang terbuat dari alumunium dinilai cukup mudah hancur dan lepas akibat aktivitas kendaran dan wisatawan yang lalu lalang setiap harinya, sehingga pemeliharanya juga dianggap kurang, selain itu pemilihan warna untuk guiding block tersebut tidak cukup membantu untuk penyandang Tuna Netra baik Blind, seperti yang ditunjukan Hallahan et al (2009) Blind atau buta total adalah kondisi dimana seseorang yang memiliki ketajaman dalam pengelihatan 20/200 atau kurang dari pengelihatan orang yang memakai kacamata atau jangkauan pengelihatan yang sempit dengan jangkauan pengelihatan tidak lebih dari 20 derajat, sedangkan low vision menurut Hallahan et al (2009) adalah istilah yang merujuk kepada seseorang atau individu yang memiliki kerusakan pengelihatan, dan kerusakan itu tidak tergolong berat, individu dengan kategori low vision masih dapat melihat maupun membaca namun dengan beberapa alat bantu pengelihatan seperti kaca pembesar dan membaca tulisan yang dicetak dengan ukuran yang besar juga.

Melihat kondisi itu diharapkan Unit Pelaksana Teknis Malioboro lebih selektif dalam pemilihan bahan, pemilihan bahan yang cukup baik yaitu guiding block yang terbuat dari ubin atau keramik, karena guiding block sendiri memiliki definisi sebagai keramik yang betekstur, selain itu biasanya berwarna mencolok, karna teksturnya yang keras dan warna nya yang mencolok juga dapat membantu mengurangi kerusakan pada material dan mudah di 
akses oleh Penyandang difabel, selanjutnya Unit Pelaksana Teknis Malioboro juga diharapkan mampu untuk lebih melihat kebutuhan Penyandang difabel di kawasan itu.

\section{Accessibility (Aksesibilitas)}

Kawasan Malioboro saat ini telah ditetapkan sebagai sebuah kawasan pedestrian, berdasarkan studinya Dharmawan (2004) pedestrian dimaknai sebagai sebuah kawasan atau area ruang luar yang di manfaatkan dan digunakan untuk berbagai kegiatan penduduk kota atau kawasan sehari-hari, contohnya untuk kegiatan berjalan-jalan, sekedar melepas lelah dan duduk santai dapat juga dijadikan sebagai tempat kampanye, selain itu fungsi ruang publik bagi pejalan kaki antara lain untuk bergerak dari satu bangunan ke bangunan yang lain, dari bangunan ke open space yang ada atau sebaliknya, atau dari suatu tempat ke tempat yang lainya di sudut kawasan ruang publik .

Realisasiya di Kawasan Malioboro masih banyak disetiap sudut kawasan lokasi ini menjadi kantong parkir sembarangan oleh berbagai kendaraan baik itu milik pedagang, pengunjung atau kendaraan online yang menjemput atau menurunkan penumpang, hal tersebut mengangu aktifitas di kawasan itu, selain itu juga keberadaan Penyandang difabel mengaku tergangu dengan keberadaan atraksi bersepeda yang disediakan oleh pemerintah kota tersebut, karena para wisatawan yang bersepeda mengunakan akses jalan yang dibuat untuk para pejalan kaki, dan para Penyandang difabel, hal itu mengangu para Penyandang difabel yang hendak mengunakan amenitas guiding block di lokasi itu. Mereka mengatakan sebaiknya ada pengaturan terkait alur untuk atraksi Jogja Bike, sehingga aktifitas tersebut tidak mengangu aktifitas wisatawan yang berkunjung atau pengguna kawasan pedestrian khususnya Penyandang difabel

\section{Ancilarry (kelembagaan)}

Kawasan Malioboro secara resmi adalah area yang dikelola oleh lembaga pemerintah yang disebut Unit Pelaksana Teknis (UPT) Malioboro, lembaga itu dibentuk berdasarkan Peraturan Walikota pada Dinas Pariwisata kota Yogyakarta, namun tidak menutup kemungkinan terdapat beberapa stakeholder yang juga memiliki peran dan terlibat di kawasan Malioboro. unit pelaksana teknis juga yang menjadi sebuah posko pengaduan untuk setiap masyarakat di kawasan itu seperti berikut ini :

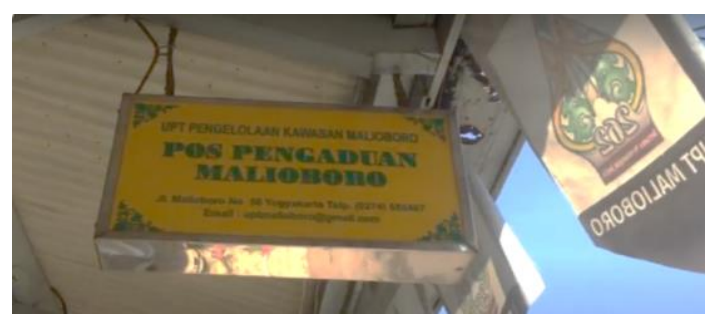

Gambar 5 : Posko pengaduan UPT Malioboro Sumber : Dokumentasi Penelitian, 2019

Dalam studinya Soerjono (2002) mendefinisikan sebuah peran sebagai sebuah aspek dinamis dari suatu kedudukan atau status yang dimiliki oleh seseorang atau lembaga tertentu, dan lembaga tersebut memiliki sebuah status yang merupakan sekumpulan hak dan kewajiban dari seseorang atau lembaga tersebut untuk dilaksanakan, sehingga apabila seseorang atau lembaga tersebut melakukan dan melaksanakan hak dan kewajibanya sesuai dengan kedudukan yang dimiliki maka seseorang atau lembaga tersebut telah menjalankan peranan nya, untuk melihat peran tersebut di Kawasan Malioboro, terdapat beberapa stakeholder yang dijabarkan pada tabel komposisi stakeholder berikut ini : 
Tabel 1

Komposisi Stakeholder

\begin{tabular}{|c|c|c|}
\hline Pemerintah & $\begin{array}{l}\text { Pengusaha } \\
\text { Pariwisata }\end{array}$ & Masyarakat Lokal \\
\hline $\begin{array}{l}\text { Unit } \\
\text { Pelaksana } \\
\text { Teknis } \\
\text { Maliboro } \\
\text { Dinas } \\
\text { Pariwisata } \\
\text { Kota } \\
\text { Yogyakarta } \\
\text { Dinas } \\
\text { Perdagang- } \\
\text { an Kota } \\
\text { Yogyakarta } \\
\text { Beberapa } \\
\text { perusahan } \\
\text { BUMN }\end{array}$ & $\begin{array}{l}\text { Akomodasi } \\
\text { Malioboro } \\
\text { Grand Inna } \\
\text { Malioboro, } \\
\text { Hotel Neo } \\
\text { Malioboro, } \\
\text { Hotel Mutiara } \\
\text { Malioboro, } \\
\text { Whiz Prime } \\
\text { Malioboro } \\
\text { Hotel, } \\
\text { Pop! Hotel } \\
\text { Malioboro, } \\
\text { Dafam } \\
\text { Fortunaa } \\
\text { Yogyakarta, } \\
\text { Cordela } \\
\text { kartika dewi } \\
\text { Malioboro, } \\
\text { Pesona Hotel } \\
\text { Malioboro, } \\
\text { Whiz Hotel } \\
\text { Malioboro, } \\
\text { HotelIbis } \\
\text { malioboro, } \\
\text { Yogyakarta }\end{array}$ & $\begin{array}{l}\text { Asosiasi pedagang } \\
\text { MalioboroPaguyuban } \\
\text { Sosrokusumo (Kuliner } \\
\text { Pagi), } \\
\text { Paguyuban } \\
\text { Handayani(kuliner } \\
\text { malam), } \\
\text { PPMS (Paguyuban } \\
\text { Pedagang Makanan } \\
\text { Siang), } \\
\text { Paguyuban Padma } \\
\text { (Angkringan), } \\
\text { PPLM (Paguyuban } \\
\text { Pedagang Lesehan } \\
\text { Malam), } \\
\text { PPKLY (Paguyuban } \\
\text { PedagangKaki Lima), } \\
\text { Paguyuban Pemalni } \\
\text { ( Souvenir), } \\
\text { Paguyuban Tridharma } \\
\text { ( Souvenir), }\end{array}$ \\
\hline & $\begin{array}{l}\text { PT Matahari } \\
\text { Department } \\
\text { Store Tbk }\end{array}$ & $\begin{array}{l}\text { Kelompok } \\
\text { Musik } \\
\text { Malioboro }\end{array}$ \\
\hline
\end{tabular}

Sumber : UPT Malioboro dan Pengelolaan Penelitian, 2019
Berdasarkan tabel 1 komposisi stakeholder tersebut yang menjadi fokus penelitian untuk di tinjau peran dan perananya lebih lanjut di penelitian ini adalah Unit Pelaksana Teknis Malioboro

1 Profil Resmi Unit Pelaksana Teknis Malioboro UPT Malioboro atau disebut juga dengan Unit Pelaksana Teknis Malioboro merupakan sebuah lembaga pemerintah yang dibentuk berdasarkan Peraturan Walikota Yogyakarta no 8 tahun 2012 pada Dinas Pariwisata kota Yogyakarta, Unit Pelaksana Teknis Malioboro ini berlokasi di Jl.Malioboro No. 56, Suryatmajan, Gedong Tengen, Kota Yogyakarta, Daerah Istimewa Yogyakarta. Peraturan Walikota tersebut memiliki kedudukan, fungsi dan tugas yang harus dijalankan, adapun yang menjadi kedudukan, fungsi dan tugas tersebut, yaitu :

Kedudukan :

a. UPT Pengelolaan Kawasan Malioboro merupakan unsur pelaksana tugas teknis operasional dan/atau kegiatan teknis penunjang tertentu berkedudukan dibawah Dinas Pariwisata

b. UPT Pengelolaan Kawasan Malioboro dipimpin oleh Kepala UPT yang berkedudukan di bawah dan bertanggung jawab kepada Kepala Dinas

Fungsi:

UPT Pengelolaan Kawasan Malioboro mempunyai fungsi sebagai penyelenggaraan ketugasan teknis operasional dan kegiatan teknis penunjang tertentu dinas dalam bidang pengelolaan pariwisata, kebersihan, keindahan, pemeliharaan sarana prasarana, pembinaan ketentraman dan ketertiban, usaha perdagangan, penataan kawasan parkir dan transportasi yang berada di Kawasan Malioboro

Tugas :

Melaksanakan fungsi sebagaimana dimaksud, UPT Pengelolaan Kawasan Malioboro mempunyai tugas :

a. Melakukan perawatan dan pemeliharaan kebersihan, pertamanan, sarana, prasarana dan fasilitas pendukung lainnya yang menjadi kewenangan UPT

b. Melakukan pemberdayaan komunitas Malioboro

c. Melakukan promosi kawasan Malioboro dan

d. Melakukan pembinaan, pengawasaan, pemantauan dan pengendalian ketentraman, ketertiban dan lalu lintas di kawasan Malioboro 
Tabel 2

Indikator keterlibatan UPT

\begin{tabular}{|c|c|c|c|}
\hline Indikator & $\begin{array}{l}\text { Terli- } \\
\text { bat }\end{array}$ & $\begin{array}{l}\text { Tidak } \\
\text { Terlib } \\
\text {-at }\end{array}$ & Keterangan \\
\hline $\begin{array}{l}\text { a. Melakukan } \\
\text { perawatan dan } \\
\text { pemeliharaan } \\
\text { kebersihan, } \\
\text { pertamanan, } \\
\text { sarana, } \\
\text { prasarana dan } \\
\text { fasilitas } \\
\text { pendukung } \\
\text { lainnya yang } \\
\text { menjadi } \\
\text { kewenangan } \\
\text { UPT }\end{array}$ & & $\nabla$ & $\begin{array}{l}\text { Pada amenitas } \\
\text { menyatakan } \\
\text { bahwa sarana } \\
\text { dan prasarana } \\
\text { Penyandang } \\
\text { difabel belum } \\
\text { terpelihara } \\
\text { dengan baik } \\
\text { dan benar } \\
\text { mengingat } \\
\text { masih banyak } \\
\text { sarana seperti } \\
\text { guiding block } \\
\text { yang rusak dan } \\
\text { hilang }\end{array}$ \\
\hline $\begin{array}{l}\text { b. Melakukan } \\
\text { pemberdayaan } \\
\text { komunitas } \\
\text { Malioboro }\end{array}$ & & $\nabla$ & $\begin{array}{l}\text { Penyandang } \\
\text { difabel masih } \\
\text { belum } \\
\text { memiliki } \\
\text { komunitas } \\
\text { sehingga } \\
\text { pemberdayaan } \\
\text { juga tidak ada } \\
\text { bagi mereka }\end{array}$ \\
\hline $\begin{array}{ll}\text { c. Melakukan } \\
\text { promosi } \\
\text { kawasan } \\
\text { Malioboro }\end{array}$ & 四 & & $\begin{array}{l}\text { Sudah } \\
\text { terpenuhi } \\
\text { dengan baik } \\
\text { terbukti } \\
\text { banyaknya } \\
\text { event di } \\
\text { kawasan itu } \\
\text { tetapi belum } \\
\text { banyak } \\
\text { melibatkan } \\
\text { Penyandang } \\
\text { difabel }\end{array}$ \\
\hline $\begin{array}{l}\text { d. } \text { Melakukan } \\
\text { pembinaan, } \\
\text { pengawasaan, } \\
\text { pemantauan } \\
\text { dan } \\
\text { pengendalian } \\
\text { ketentraman, } \\
\text { ketertiban dan } \\
\text { lalu lintas di } \\
\text { kawasan } \\
\text { Malioboro }\end{array}$ & & D & $\begin{array}{l}\text { Pembinaan } \\
\text { untuk } \\
\text { Penyandang } \\
\text { difabel sendiri } \\
\text { belum ada, } \\
\text { namun untuk } \\
\text { komunitas lain } \\
\text { dan aspek lain } \\
\text { sudah }\end{array}$ \\
\hline
\end{tabular}

1 Fungsi Pemberdayaan

Melihat masih minim nya kawasan ini dengan aspek pemberdayaan baik dari Dinas Pariwisata Kota Yogyakarta dan Unit Pelaksana Teknis Malioboro, diharapkan mampu mengidentifikasi kondisi yang sebenarnya dari para Penyandang difabel di kawasan ini, berikut beberapa hal yang diperoleh melalui hasil observasi dan wawancara, terkait peran Unit Pelaksana Teknis Malioboro terhadap Penyandang difabel yang masih kurang dan butuh untuk direalisasikan:

a. Pembentukan komunitas Penyandang Difabel

b. Pemberdayaan komunitas untuk Penyandang Difabel

c. Penguatan kelembagaan dan komunitas pariwisata serta memperluas Jaringan kerjasama di kawasan Malioboro

d. Pendampingan pada pelibatan Penyandang difabel di event atau acara sosial

e. Pemantauan terhadap amenitas untuk penyandang difabelbaik wisatawan maupun masyarakat lokal.

Melihat kenyataan di Kawasan Malioboro terhadap Penyandang difabel oleh Unit Pelaksana Teknis Malioboro masih banyak kekurangan dan masih belum adanya upaya pemberdayaan, sehingga sangat diperlukan strategi untuk melakukan pemberdayaan, dan untuk melakukan hal itu sangat perlu dilakukan analisis, dan pada penelitian ini digunakan analisis SOAR :

\section{Strength}

Kekuatan terbesar yang dimiliki Kawasan Malioboro terletak pada jumlah kunjungan yang begitu pesat, selain itu potensi yang dimilki setiap Difabel di Kawasan Malioboro cukup bervariasi, hal tersebut akan membawa perubahan lebih baik apabila potensi itu diperhatikan oleh Unit Pelaksana Teknis Malioboro dalam menyediakan komunitas khusus dan memberdayakan langsung komunitas tersebut 


\section{Opportunity}

Kawasan ini memiliki beragam aktifitas dan event baik event budaya maupun modern, melihat begitu banyak event yang diselengarakan oleh berbagai pihak di Kawasan Malioboro, hal itu dapat dijadikan sebagai peluang untuk melibatkan Penyandang difabel oleh para stakeholder, pelibatan tersebut bisa berupa pengemasan tampilan pertunjukan alat musik, seni tari atau seni suara, yang disesuaikan dengan event yang akan dilakukan, berikut tabel event yang diselenggarakan di kawasan Malioboro :

\section{Tabel 3}

Kalender event di Malioboro

\begin{tabular}{|c|c|}
\hline Month & Event Schedule \\
\hline February & $\begin{array}{l}\text { Tioghoa culture festival, } \\
\text { Jogja heboh, Temu kangen Jogja }\end{array}$ \\
\hline March & $\begin{array}{l}\text { Themporary exhibitions and Theaterical, } \\
\text { Wedd Expo, Cultural Attraction of } \\
\text { repositioning of puro pakualaman }\end{array}$ \\
\hline April & $\begin{array}{l}\text { Manoreh Night Spectacular, } \\
\text { Revitalisasi Seni, Orchestra Music, } \\
\text { Malioboro KulineRUN }\end{array}$ \\
\hline May & $\begin{array}{l}\text { Apeman Malioboro } \\
\text { Artjogja }\end{array}$ \\
\hline June & $\begin{array}{l}\text { Batik Fashion and Exhibition } \\
\text { and Handy craft, Garebeg Sawal, } \\
\text { Numplak,Wajik }\end{array}$ \\
\hline July & $\begin{array}{l}\text { Jogja Hard Enduro, dan Back to school } \\
\text { event }\end{array}$ \\
\hline Agust & $\begin{array}{l}\text { Jcm Festival sate, Independence day, } \\
\text { Pagelaran karawitan, Jogja Fashion } \\
\text { Week, Bedog art Festival }\end{array}$ \\
\hline September & Pagelaran theater, Asi tri Festival \\
\hline October & $\begin{array}{l}\text { Wayang Jogja, Malioboro night festival, } \\
\text { Yogyakarta Contemporer music festival }\end{array}$ \\
\hline November & $\begin{array}{l}\text { Kontemporer Dance, Kembul Sewu Dulur, } \\
\text { Festival, Dagelan Mataram }\end{array}$ \\
\hline
\end{tabular}

Sumber : UPT Malioboro dan pengelolaan peneliti 2019

\section{Aspiration}

kondisi ini ditentukan oleh masing-masing stakeholder disebuah kawasan, pada Kawasan Malioboro terdiri atas beberapa stakeholder yang ada pada Tabel 1 berikut ini beberapa stakeholder yang menyampaiakan aspirasinya untuk Penyandang difabel di Kawasan Malioboro yaitu : a. Unit Pelaksana Teknis Malioboro sangat mengharapkan sekiranya agar jumlah Penyandang difabel yang berperan untuk memperoleh keuntungan ekonomi dari aktifitas pariwisata tidak meningkat dan cukup dengan jumlah yang sama

b. Dinas Pariwisata Kota Yogyakarta, mengharapkan apabila memang ada data Penyandang difabel di seputaran Kawasan Malioboro yang tidak terlibat dan tidak terdaftar, dapat mendaftarkan diri, karena berdasarkan data yang mereka punya, selama ini tidak ada laporan terkait hal tersebut.

c. Penyandang difabel mengharapkan agar Unit Pelaksana Teknis Malioboro lebih memperhatikan kebutuhan dan memberikan kesempatan yang sama untuk mereka melalui program unit pelaksana teknis. Selain itu mereka juga berharap ada forum yang dapat mereka gunakan untuk menyampaikan aspirasi mereka terkait amenitas Penyandang difabel

d. Penyandang difabel juga berharap agar Dinas Pariwisata dan UPT Malioboro dapat meilbatkan mereka pada event yang ada di Malioboro seperti Art Jogja, Orchestra, Malioboro Night Festival dan lainya sesuai dengan potensi yang dimiliki masing-masing Difabel

e. Penyandang difabel mengharapkan agar ada program untuk melihat dan mengembangkan potensi yang mereka miliki

\section{Result}

Result merupakan sebuah cara yang digunakan untuk menentukan ukuran dari hasil-hasil yang ingin dicapai atau hasil yang diharapkan setiap elemen. Faktor hasil yang terukur itu dirumuskan dari berbagai faktor yang ada, yaitu faktor kekuatan, faktor peluang dan faktor aspirasi yang akan melahirkan suatu perencanaan yang cukup strategis sebagai sebuah alternatif.

Strategi yang dilahirkan pada penelitian ini yaitu strategi pemberdayan untuk Penyandang difabel di kawasan Malioboro, strategi ini nantinya akan menghasilkan hasil-hasil yang terukur sesuai dengan apa yang Penyadang Difabel di Kawasan Malioboro harapkan untuk kondisi dimasa depan. Hal tersebut dapat dilihat pada matriks identifikasi yang mengunakan Analisis Soar sebagai berikut 
Tabel 4

Identifikasi SOAR

\begin{tabular}{|ll}
\hline \multicolumn{2}{|l}{$\begin{array}{l}\text { Strength } \\
\text { (Kekuatan) }\end{array}$} \\
\hline a. & Jumlah Kunjungan \\
& wisatawan di \\
& Kawasan Malioboro \\
& yang selalu \\
& meningkat
\end{tabular}

b. Potensi Penyandang difabel yang beragam (Seni tari, musik, Seni Suara, buat kerajinan, Berdagang)

c. Tersedianya fasilitas umum yang memadai untuk Penyandang difabel

d. Kesadaran Para Penyandang difabel Untuk mau diwadahi kearah pemberdayaan
Oppurtunity

(Kesempatan)

a. Banyaknya Eventevent Festival budaya maupun modern di kawasan Malioboro

b. Organisasi Penyandang difabel Di Yogyakarta mau ikut terlibat membantu

c. Peluang Pelatihan dan Workshop di Luar Lembaga UPT, yang dapat menambah wawasan, Pelatihan seni dan lainya

d. Banyak lembaga dan stakeholders di kawasan tersebut yang bisa dijadikan acuan investor

Result

Aspiration

(Aspirasi)

(Hasil yang diharapkan)

a. Unit pelaksana

teknis Malioboro

diharapkan

memberikan wadah untuk edukasi dan

pemberdayaan

kepada para

Penyandang difabel

b. Diharapkan untuk memelihara amenitas dan akses untuk Penyandang difabel di Kawasan Malioboro yang rusak akibat aktifitas kendaran dan pedagang kaki lima yang akan menutupi amenitas tersebut

c. Pedagang kaki lima diharapkan untuk tidak menutupi Amenitas guiding block yang disediakn untuk

Penyandang difabel

agar dapat berjalan

sesuai fungsi

amenitas tersebut

dibuat

d. Perlu adanya Bantuan dari Dinas Pariwisata terkait kebijakan yang diberlakukan untuk Penyandang difabel

e. Dilibatkan pada event-event pariwisata di Malioboro sesuai dengan Potensi yang dimiliki

Sumber: Hasil Penelitian, 2020

Berdasarkan identifikasi SOAR di atas terungkap secara pemahaman lintas budaya terlihat pentingnya mensinergikan ekspektasi berbeda dari masingmasing pihak (Mahagangga, dkk., 2017). Antara para penyandang difabel dan pemerintah (unit pelaksana teknis) serta masyarakat memiliki kesenjangan ekspektasi. Harapan besar jika temuan identifikasi SOAR di atas dapat menjadi kunci komunikasi untuk pencapaian tujuan yang saling menguntungkan diantara pihak-pihak yang berkepentingan.

\section{Kesimpulan}

Peran Unit Pelaksana Teknis Malioboro terhadap pemberdayaan Penyandang difabel di Kawasan Malioboro, Antara Lain :

1 Berdasarkan kondisi realitas berdasarkan komponen 4a Penyandang difabel di Kawasan Malioboro

a Atraksi, Di kawasan Malioboro yang menjadi Atraksi utama yaitu Wisata belanja dan Wisata kuliner, selain itu terdapat beberapa atraksi tambahan lainnya seperti Jogja Bike, Pasar Beringharjo, dan lainya, namun pelibatan para Penyandang difabel pada atraksi di kawasan ini masih belum mendapat perhatian

b Amenitas, Unit Pelaksana Teknis Malioboro juga telah berupaya membangun fasilitasfasilitas khusus untuk para Penyandang Difabel, seperti guiding block di sepanjang Kawasan Malioboro guna mempermudah bagi penyandang Tuna Netra, fasilitas tersebut ternyata belum cukup aksesible karena material yang digunakan adalah material yang terbuat dari alumunium dan 
berwarna abu-abu, tekstur material yang terbuat dari alumunium dinilai cukup mudah hancur dan lepas akibat aktivitas kendaran dan wisatawan setiap harinya, selain tekstur pemilihan warna untuk guiding block tersebut tidak cukup membantu untuk penyandang tuna netra dengan berbagai kategori

c Aksesibilitas, Kawasan Malioboro saat ini menetapkan posisi sebagai kawasan yang semi pedestrian yang pada prinsipnya diperuntukan bagi pejalan kaki dan kendaraan tradisional, pada realisasinya di Kawasan Malioboro banyak disetiap sudut kawasan menjadi kantong parkir sembarangan oleh berbagai kendaraan, dan Keberadaan Penyandang difabel mengaku tergangu dengan keberadaan tersebut

d Ancilary, Kawasan Malioboro di kelola oleh Unit Pelaksana Teknis Malioboro, UPT tersebut memiliki Tugas kedudukan dan fungsi sebagai lembaga pengelolaan, dan berdarakan Tugas, kedudukan dan Fungsi nya, UPT dinyatakan belum melaksanakan perananya terkait point pemberdayan kepada setiap komunitas Di Malioboro seperti yang tertera pada tugas UPT

2 Strategi tersebut di identifikasi dan di analisis berdasarkan Analisis SOAR dengan sinergi ekspektasi budaya yang dapat diwujudkan melalui komunikasi program, yaitu :

a. Strength atau kekuatan terbesar di Kawasan Malioboro yang dapat dijadikan aset oleh Penyandang difabel ataupun UPT adalah Jumlah Kunjungan yang selalu padat

b. Oppurtunity, atau peluang terbesar yang dimiliki oleh Kawasan Malioboro yang dapat di manfaatkan oleh UPT maupun Penyandang difabel adalah event-event yang diselengarakan di kawasan tersebut

c. Aspiration, Di kawasan Malioboro terdapat banyak stakeholder pariwisata, dan harapan yang paling besar terletak pada Penyandang difabel di kawasan tersebut untuk lebih di perhatikan keberadaanya, dibentuk juga komunitas, kemudian dipelihara fasilitas yang mereka miliki sebagai sebuah asset dan dilibatkan dalam kegiatan-kegiatan lain

d. Result, UPT Malioboro diharapkan untuk membentuk sebuah komunitas khusus untuk pemberdayaan Penyandang Difabel, kemudian komunitas yang diberdayakan tersebut dilibatkan dan di berikan perhatian untuk sebuah pengemasan atraksi wisata baru di Kawasan Malioboro sehingga dapat memberi citra pemberdayaan yang baik.

\section{DAFTAR PUSTAKA}

Abdussalam H. (2007) Kriminologi. Jakarta: Restu Agung.

Bungin B. (2007) Penelitian kualitatif: komunikasi, ekonomi, kebijakan publik, dan ilmu sosial lainnya. Jakarta: Kencana.

Cooper C. (2008). Tourism: Principles and practice. Harlow: Pearson education.

Doddy D. (2004) Mengamati Peran Pedestrian dalam Kehidupan Sosial Ekonomi Masyarakat Studi Kasus SudirmanThamrin. Jakarta: Skripsi Tugas Akhir Jurusan Arsitektur Universitas Muhammadiyah

Hallan, D.P., Kauffman, J. M., \& Pullen, P. C. (2009). Exceptional Learners (11th ed). USA: Pearson Education, Inc.

Mahagangga, IGAO, et. all. 2020. Tourism Evolution in Badung Regency Bali in Conference: The 5th International Conference on Climate Change, Sebelas Maret University, Indonesia, 24-25 September 2020. Research gate link. Number of DOI: $10.13140 /$ RG.2.2.34920.29449

Mahagangga, I. G. A. O., \& NUGROHO, S. (2017). Pemahaman lintas budaya dalam kepariwisataan. Cakra Press bekerja sama dengan Fakultas Pariwisata, Universitas Udayana.

Pranarka, A. M. W. (1996). Pemberdayaan: konsep, kebijakan, dan implementasi. Jakarta: Centre for Strategic and International Studies.

Prastowo, A. (2011). Metode penelitian kualitatif dalam perspektif rancangan penelitian. Yogyakarta: Ar-Ruzz Media

Putri, D,F,I (2015). Peran Unit Pelaksana Teknis Dinas (UPTD) Pondok Sosial Kalijudan Kota Surabaya Dalam Pembinaan Anak Penyandang Tunagrahita. Surabaya: Publika

Purita, E. D.(2013) Pengelolaan Transportasi Umum di Jalan Malioboro. Yogyakarta.: Skripsi Universitas Negeri Yogyakarta

Saidah, D. (2016). Pemberdayaan masyarakat difabel melalui keterampilan handicraft: tuna rungu wicara di yayasan rumah regis tanjung barat jakarta selatan (Bachelor's thesis, UIN Syarif Hidayatullah Jakarta: Fakultas Ilmu Dakwah dan Ilmu Komunikasi.

Soejono,S.(2002). Teori Peranan. Jakarta: Bumi Aksara

Soejono,S.(1990). Sosiologi Suatu Pengantar. Jakarta: Rajawali Pers

Stavros J, Cooperrider D, \& Kelley, D. L. (2003). Strategic inquiry appreciative intent: inspiration to SOAR, a new framework for strategic planning, Amsterdam: Ai Practitioner, 11.

Suryawan, I. B., \& Mahagangga, I. G. A. O. (2017). Penelitian Lapangan 1. Denpasar: Cakra Media dan Fakultas Pariwisata Universitas Udayana.

PERATURAN PERUNDANG-UNDANGAN

Peraturan Walikota Yogyakarta No 135 Tahun 2017 Tentang Pembentukan, Susunan, Organisasi, Kedudukan, Fungsi, Tugas dan Tata Kerja Unit Pelaksana Teknis Malioboro pada Dinas Pariwisata Kota Yogyakarta

Undang-undang Republik Indonesia no 10 tahun 2009. Tentang Kepariwisataan

Undang-undang Republik Indonesia no 8 tahun 2016. Tentang Penyandang Difabel

Undang-undang Republik Indonesia no 13 tahun 2003 Tentang Ketenagakerjaan 